\title{
Fully covered self-expanding metal stents in the management of difficult common bile duct stones
}

\author{
Jesús García-Cano, Amanda Karolina Reyes-Guevara, Teresa Martínez-Pérez, Laura Valiente-González, \\ Raquel Martínez-Fernández, Miriam Viñuelas-Chicano, Carmen Julia Gómez-Ruiz, Julia Morillas-Ariño, \\ Gracia Pérez-Vigara, José Ignacio Pérez-García and Ángel Pérez-Sola
}

Department of Digestive Diseases. Hospital Virgen de la Luz. Cuenca, Spain

\begin{abstract}
Background and objectives: plastic biliary stents are often used after an ERCP session without complete common bile duct stones (CBDS) extraction. Sometimes, the volume of biliary drainage with these stents may be insufficient. We present our experience with the use of fully covered self-expanding metal stents (FCSEMS) in the setting of incomplete CBDS extraction.

Patients and methods: after an ERCP session with difficult CBDS not completely removed, biliary FCSEMS (Wallflex) were inserted in some patients when it was deemed that biliary sphincterotomy and a single plastic stent would not provide an adequate drainage.

Results: a retrospective study was performed. Biliary FCSEMS were inserted in 29 patients, mean age 81 years. CBDS could not be extracted through a biliary sphincterotomy due to its large size $(n=18)$ or because of the presence of inflammatory distal strictures $(n=11)$. The greatest biliary drainage with shortest ERCP time was considered mandatory due to clinical instability of patients and/or poor tolerance to conscious sedation administered by the endoscopist. Successful biliary drainage was obtained in all cases. FCSEMS were removed after a median of 199.5 days in 16 patients with a complete CBDS extraction in 15 (93.7\%). FCSEMS were not removed in the remaining 13 patients due to their clinical condition, and a wait-and-see strategy was undertaken.

Conclusions: in selected cases, utilization of removable FCSEMS can be a good option for a quick and adequate biliary drainage in the setting of difficult CBDS. Because of the higher cost of these stents its use needs to be individualized.
\end{abstract}

Key words: ERCP. Difficult common bile duct stones. Biliary plastic stents. Fully covered self-expanding metal stents.

García-Cano J, Reves-Guevara AK, Martínez-Pérez T, ValienteGonzález L, Martínez-Fernández R, Viñuelas-Chicano M, GómezRuiz CJ, Morillas-Ariño J, Pérez-Vigara G, Pérez-García JI, PérezSola A. Fully covered self-expanding metal stents in the management of difficult common bile duct stones. Rev Esp Enferm Dig 2013;105:7-12.

Received: $20-08-2012$

Accepted: 20-01-2013

Correspondence: Jesús García-Cano. Department of Digestive Diseases. Hospital Virgen de la Luz. C/ Hermandad Donantes de Sangre, s/n. 16002 Cuenca. Spain e-mail: endoscopia@endoscopiaintervencionista.org

\section{INTRODUCTION}

For nearly 40 years endoscopic retrograde cholangiopancreatography (ERCP) with biliary sphincterotomy has been the treatment of choice to remove common bile duct stones (CBDS). Since 2003, biliary sphincterotomy balloon dilation or sphincteroplasty is used for difficult cases with very good results (1). Complicated CBDS are usually those with more than $10 \mathrm{~mm}$ in diameter, multliple, impacted stones in the bile duct, concretions of hard consistency, peridiverticular situation of the ampulla, tortuosity or narrowing of the distal common bile duct and other conditions arising from the patient, like coagulation disorders (2).

Plastic stents are the most used palliative method when after an ERCP session all CBDS cannot be removed. Friction between stones and stents produce the CBDS to fragment and shrink or become mud in a period of time from 3 to 6 months. Afterwards, the vast majority of CBDS can be removed fairly easily after a second ERCP session. For the remaining stones it is necessary to use certain forms of lithotripsy, such as mechanic lithotripsy. However, some CBDS may even continue without being extracted (3).

Sometimes, ursodeoxycholic acid is added to plastic stents. As other solutions, such as terpene choleretic, they have the property to make more soluble cholesterol, calcium carbonate and phosphate. In this way, CBDS get smaller and their extraction is facilitated in new ERCP sessions (4).

Since the introduction of easily removable biliary selfexpanding metal stents (SEMS), several studies had focused on its use in the treatment of difficult CBDS (2,5-7). SEMS were used both as slow dilation method of the papilla of Vater to proceed on subsequent CBDS extraction and also to achieve similar effects to those of plastic stents, but SEMS were used in more complex cases. Besides, recently introduced biliary fully covered SEMS (FCSEMS) have been also employed successfully in the treatment of other benign biliary conditions (8). 
We analyzed our experience in the management of complex CBDS with FCSEMS.

\section{PATIENTS, MATERIAL AND METHODS}

FCSEMS were used by us in the setting of complex CBDS in which they could not be extracted during ERCP and it was deemed that a biliary sphincterotomy and a plastic stent did not offer a sufficient biliary drainage. Inability to perform more endoscopic maneuvers such as the insertion of multiple plastic biliary stents, biliary sphincterotomy dilation, lithotripsy within the bile duct, etc. became usually conditioned for the necessity of performing the ERCP in the shortest achievable time.

Swiftness to finish the endoscopic intervention was due to the unstable situation of patients and/or poor tolerance to conscious sedation with midazolam and fentanyl administered by the endoscopist.

All procedures were performed by the same endoscopist, with 15 years experience, using a $\mathrm{C}$-arm fluoroscopy device in the endoscopy unit. A Pentax duodenoscope with therapeutic channel was employed.

During the study period, ERCP sedation was administered in our center by the physician and the nurse involved in the intervention. This practice is still prevalent in many endoscopy units.

The Wallflex biliary FCSEMS (Boston Scientific) was employed in the study. This stent is made of platinol and has a Permalume membrane coating, resistant to corrosion produced the bile and other upper digestive tract juices. This kind of covering (probably similar to other types of

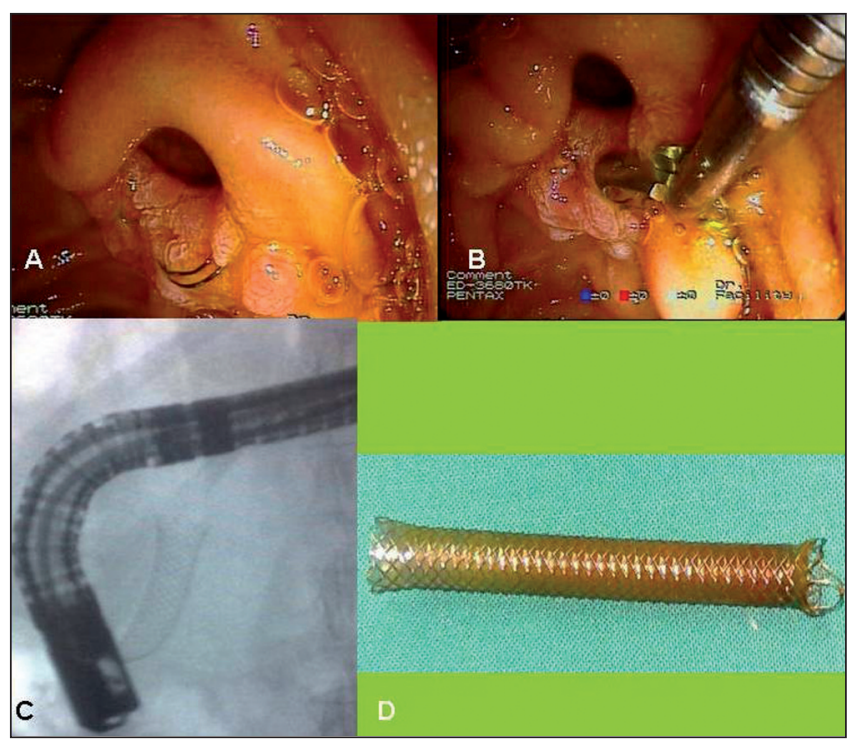

Fig. 1. A. After 134 days of stent insertion only a tiny portion of the extractor washer is seen in the papilla. B. Extraction with a foreign bodies forceps. $C$. The stent can be removed through the working channel of the duodenoscope. D. Integrity of the stent after removal. coatings) prevents the stent from embedding in the bile duct making very difficult or impossible its removal as it occurs with bare SEMS.

Stent insertion was made over a 0.025 inch and $260 \mathrm{~cm}$ length and length guide wire that had previously been inserted into the intrahepatic biliary tree, above the CBDS. The undeployed stent has 8 French in diameter. Once fully open, it expands up to 8 or $10 \mathrm{~mm}$ depending on the model, with lengths varying between 6 to $8 \mathrm{~mm}$.

The deployment mechanism is similar to most SEMS. The outer sheath that contains folded the stent is slide back whilst release begins at its distal part. Stent opening leads to a progressive shortening that must be continuously corrected to prevent from remaining the entire stent completely inside the bile duct.

To facilitate extraction, the duodenal portion was placed into the duodenum more prominent than in stents placed permanently for neoplasms. According to our previous experience with these FCSEMS we tried to remove them within a maximum of 180 days (about six months). Although the duodenal end of the stent had been located sufficiently away from the papilla, metallic tissue, even being entirely coated, always induces some kind of hyperplasia that can hide the distal washer extractor (Figure 1). This ring is entirely woven with the filamentary structure of the stent in a way that does not break when pulling it and facilitates its removal. Anyway, stent removal trying to complete CBDS clearance was determined according to the clinical situation and individual assessment for each patient. We did not apply any rigid schedule.

For stent extraction a new ERCP was performed. The stent was grasped by the washer extractor or at its distal end with a foreign bodies extraction forceps. After mobilizing, extraction was completed through the working channel of the duodenoscope without removing the entire instrument from the duodenum (Figure 1). Cholangiography was made again to assess the previously not removed CBDS situation and new attempts of extraction were performed.

After ERCP procedures (insertion and removal) patients were admitted at least overnight to rule out possible complications. Success in biliary drainage was monitored by clinical and laboratory data.

Study analysis is retrospective although patients were prospectively included in a specific ERCP database at our institution.

\section{RESULTS}

Study period comprehended 40 months (January 2008March 2012). During this time 175 ERCP for CBDS were performed in our institution. FCSEMS were used in 29 patients $(16.6 \%)$. There were 15 women and 14 men with a mean age of 81 years (SD 11, range 68-95) (Table I). After bile duct deep cannulation all patients underwent a biliary sphincterotomy. CBDS could not be extracted in 
Table I. Characteristics of patients with difficult common bile duct stones who had a fully covered self-expanding metal stent (FCSEMS) inserted to drain the biliary tree. Indication for FCSEMS insertion were clinical instability during ERCP and/or bad tolerance to conscious sedation

\begin{tabular}{|c|c|c|c|c|c|c|}
\hline Patient & Genderlage & $E R C P$ reason & $\begin{array}{l}\text { Indication for } \\
\text { FCSEMS }\end{array}$ & $\begin{array}{c}\text { Days with } \\
\text { stent in place }\end{array}$ & $\begin{array}{c}\text { Distal inflammatory } \\
\text { stricture }\end{array}$ & $\begin{array}{l}\text { FCSESMS } \\
\text { removed }\end{array}$ \\
\hline 1 & M/83 & Jaundice & Instability & 130 & No & No \\
\hline 2 & F/85 & Jaundice & Bad tolerance & 273 & Yes & No \\
\hline 3 & $\mathrm{~F} / 77$ & Jaundice & Instability & 134 & No & Yes \\
\hline 4 & F/85 & Cholangitis & Instability & 290 & No & No \\
\hline 5 & F/93 & Jaundice & Instability & 370 & No & No \\
\hline 6 & F/86 & Jaundice & Instability & 255 & Yes & No \\
\hline 7 & $\mathrm{M} / 87$ & Cholangitis & Instability & 370 & No & No \\
\hline 8 & $\mathrm{~F} / 87$ & Jaundice & Instability & 390 & No & No \\
\hline 9 & $\mathrm{M} / 80$ & Jaundice & Bad tolerance & 130 & Yes & Yes \\
\hline 10 & $F / 76$ & Cholangitis & Instability & 370 & Yes & No \\
\hline 11 & $\mathrm{M} / 77$ & Jaundice & Instability & 320 & No & Yes \\
\hline 12 & F/83 & Biliary fistula & Bad tolerance & 300 & No & Yes \\
\hline 13 & $\mathrm{M} / 68$ & Cholangitis & Bad tolerance & 210 & Yes & Yes \\
\hline 14 & M/95 & Cholangitis & Instability & 371 & No & No \\
\hline 15 & F/75 & Jaundice & Bad tolerance & 285 & No & Yes \\
\hline 16 & $\mathrm{M} / 73$ & Jaundice & Instability & 90 & Yes & Yes \\
\hline 17 & $\mathrm{~F} / 77$ & Jaundice & Bad tolerance & 300 & Yes & Yes \\
\hline 18 & $\mathrm{~F} / 78$ & Cholangitis & Instability & 258 & Yes & Yes \\
\hline 19 & $\mathrm{M} / 87$ & Jaundice & Instability & 453 & No & No \\
\hline 20 & F/86 & Cholangitis & Instability & 372 & No & No \\
\hline 21 & M/85 & Cholangitis & Instability & 389 & Yes & No \\
\hline 22 & M/77 & Jaundice & Bad tolerance & 259 & Yes & Yes \\
\hline 23 & M/91 & Jaundice & Bad tolerance & 306 & No & No \\
\hline 24 & M/79 & Jaundice & Bad tolerance & 297 & Yes & Yes \\
\hline 25 & F/80 & Jaundice & Bad tolerance & 189 & No & Yes \\
\hline 26 & $\mathrm{M} / 78$ & Cholangitis & Instability & 157 & No & Yes \\
\hline 27 & $\mathrm{~F} / 70$ & Jaundice & Bad tolerance & 113 & No & Yes \\
\hline 28 & $\mathrm{M} / 84$ & Jaundice & Instability & 30 & No & Yes \\
\hline 29 & $\mathrm{~F} / 80$ & Jaundice & Bad tolerance & 123 & No & Yes \\
\hline
\end{tabular}

F: female; M: male.

18 cases because they were large or multiple (Figure 2). In 11 patients, besides the size, common bile duct distal inflammatory strictures were encountered (Figure 3). ERCP was performed in 17 patients with significant

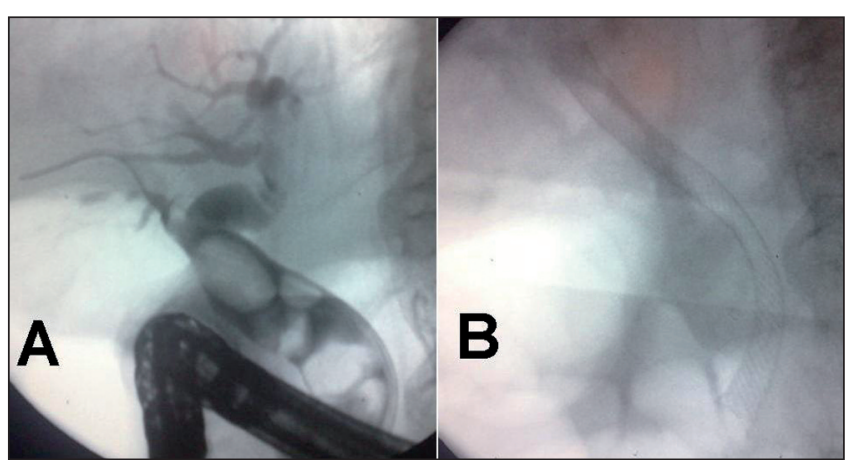

Fig. 2. A. Multiple large common bile duct stones. B. Drainage by means of fully covered self-expanding metal stent. comorbidity and unstable clinical situation. One of them, 95 years old (Table I, patient 14) suffered a cardiac arrest during ERCP and had to be intubated. ERCP was finalized with anesthetic monitoring (Figure 4). The remaining 12 patients had poor tolerance to conscious sedation administered by the endoscopist and FCSEMS insertion was decided in order to achieve an adequate biliary drainage. FCSEMS diameters $(\mathrm{mm})$ and lengths $(\mathrm{cm})$ used were: 22 times $8 \times 8$, four $8 \times 6$ and in three patients 10x6. Successful biliary drainage was obtained in all ERCP. Eighteen patients had gallbladder in place. Eight $\mathrm{mm}$ diameter FCSEMS were used in them with the intention of not to obstruct the cystic duct. Needle-knife precut technique had to be used in three patients to gain the common bile duct. Two of them suffered from moderate post-ERCP acute pancreatitis and the third one had severe bleeding that required the infusion of recombinant factor VII. The stent alone was incapable to stop the bleeding.

Stents were removed after a median of 199.5 days in 16 patients. Theoretically, extraction had been scheduled for a 


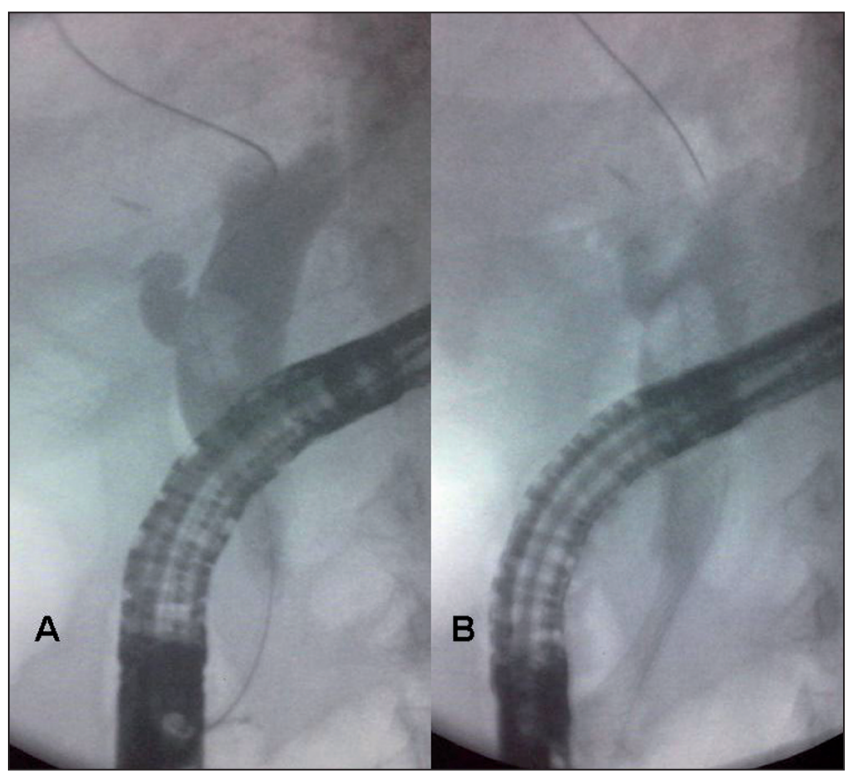

Fig. 3. A. Large stone with distal common bile duct inflammatory stricture. B. Insertion of fully covered self-expanding metal stent.

maximum of 180 days. However, various factors such as the refusal of some elderly patients to new ERCP or loss of follow up made the extraction time exceeded the expected duration.

FCSESMS could be easily removed in 13 patients. In other three the duodenal end was completely buried in normal papillary mucosa and they had a more complex extraction procedure. Removal was possible by using a dilatation balloon inflated inside the stent in one occasion and pulling with a stone extraction balloon in the other two (Figure 5). These FCSEMS had been inserted for 320, 285 and 240 days respectively. Therefore, extraction succeeded in $100 \%$ (16/16) of the attempted stents. Complete CBDS clearance was achieved in 15/16 (93.7\%). In 10/16 (62.5\%) extraction balloon sweep was enough. In the remaining patients biliary sphincterotomy dilation had to be performed.

Only 5 of these second procedures were done under sedation by an anesthesiologist. The patient without complete stone removal had already a stable clinical condition and double pigtail type plastic stents were used. The other 13 patients refused a new ERCP and they underwent periodic controls in outpatient's clinic or watchful follow up. Patients and their relatives were informed about symptoms and signs of biliary obstruction and when to search medical assistance.

At a median of 240 days (range 30-360) no episodes of stent dysfunction were observed. Furthermore, no mortality or serious complications were found in this series secondary to biliary Wallflex FCSEMS insertion.

\section{DISCUSSION}

The purpose for using FCSEMS in this series of patients was to achieve the maximum biliary drainage with shortest

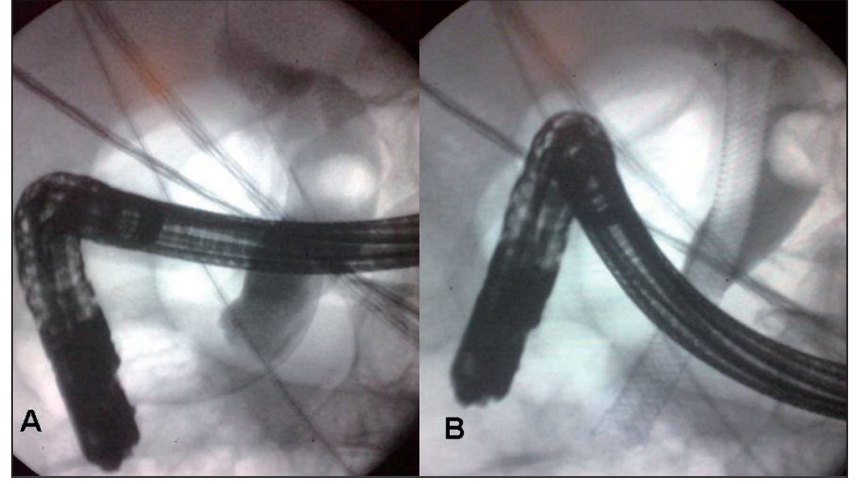

Fig. 4. A. Large common bile duct stone in a 95 years old patient who suffered a cardiac arrest during ERCP. B. After intubation and anesthetic monitoring a fully covered self-expanding metal stent was placed.

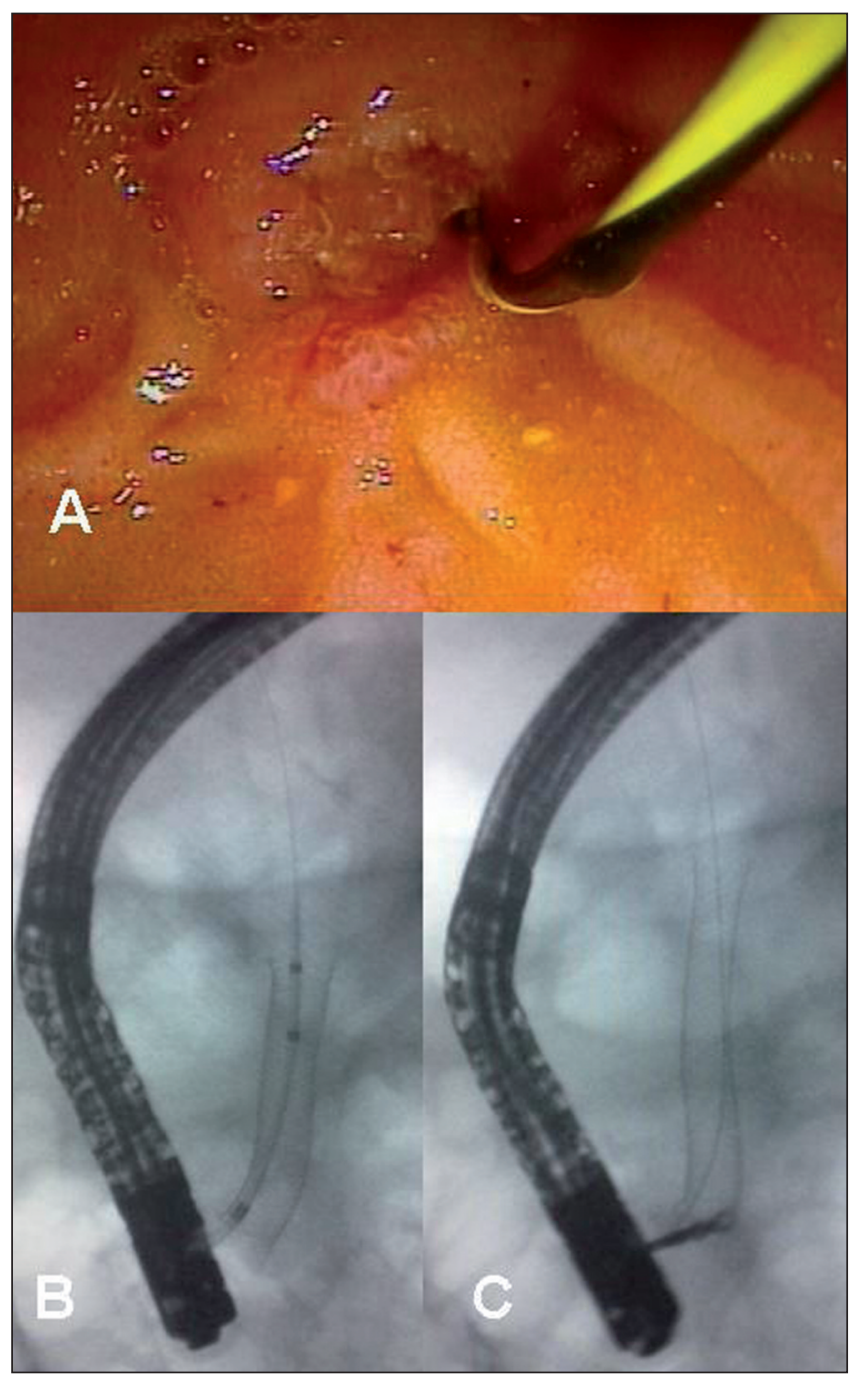

Fig. 5. A. After 285 days of insertion the stent duodenal end was completely covered. B. The stent was pulled out several times from its upper end using a $15 \mathrm{~mm}$ extraction balloon. C. Finally the extractor washer appeared in the papilla allowing extraction. 
ERCP time. The size and number of CBDS did not appear achievable that the sphincterotomy and a plastic stent could offer a satisfactory bile duct decompression. A large proportion of patients had clinical instability and other poor tolerance to conscious sedation.

Insertion of a single FCSEMS is usually faster than placement of several plastic stents. This figure is an objective fact that, unfortunately, cannot be reported. Because of the retrospective nature of the study it was not measured.

It is true that if these ERCPs would have been performed under anesthetic monitoring or using deep sedation they could have ended up in a different way. However, the study reflects the real situation of many endoscopists.

A FCSEMS costs about ten times more than a plastic one. Further randomized studies are necessary to determine whether in similar cases to those presented, the price of a FCSEMS could be offset by the decrease of other devices and resources (multiple plastic stents, several procedures...) and hospital stay after the effective and rapid resolution achieved in biliary obstruction.

In patients who agreed to a second ERCP, bile duct clearance was achieved in $93.7 \%$ and in more than a half only extraction balloon sweep was necessary after stent removal.

The mechanism by which CBDS size decreases can be fragmentation following FCSEMS expansion or by friction during breathing movements. Besides, papillary dilation is caused by the stent (2). In most patients, the second ERCP was also conducted with conscious sedation administered by the endoscopist. Nevertheless, patients had clinical stability and stent removal and common bile duct clearance were simpler once the papilla had been cannulated and the sphincterotomy performed in the first endoscopic intervention.

It has been known for long that CBDS size is one of the most important factors to achieve complete stone removal in the first ERCP session. In the study of Lauri et al. (9) made in 1993, it was observed that CBDS up to $10 \mathrm{~mm}$ or smaller could almost always be extracted. While extraction was only possible for $12 \%$ of stones having a diameter of $15 \mathrm{~mm}$ or greater.

A previous magnetic resonance cholangiopancreatography study can help to plan in advance the most appropriate endoscopic maneuvers.

Tapering of the distal common bile duct, sometimes difficult to distinguish from inflammatory strictures, is another critical success factor in the extraction rate (10). Today, the widespread use of biliary sphincterotomy dilation which also includes a portion of the suprapapillary common bile duct can solve this problem. But always keeping in mind that balloon dilation to a much larger diameter than the distal common bile duct can produce perforation.

In the majority of retained CBDS after ERCP, plastic stents are the most employed temporizing measure (11-19). This solution is good in the first months after the index ERCP, but in the long term, there can be major complications such as cholangitis (20). However, this treatment may be appropriate in elderly patients or with significant morbidity.
Plastics stents decrease CBDS size and make it easier to extract in further ERCPs. In cases of distal common bile duct narrowing or stricture, progressive dilatation with FCSEMS or plastic stents may be less aggressive and dangerous that forced balloon dilation. Any type of plastic stents can be used. Many endoscopists prefer double pigtail stents because the straight ones can migrate more easily and if they are longer than $9 \mathrm{~cm}$ in length can cause duodenal perforation. In one study $(21,22)$ it has been observed that simultaneously multiple pigtails insertion in not extracted CBDS, can improve bile drainage. However, several plastic stents insertion is more complex, takes longer and can obtain a smaller drainage volume than a single FCSEMS insertion.

A $16.6 \%$ rate of FCSEMS in this group of patients may seem high. In previous studies in our center we have obtained a $94.5 \%$ rate of complete CBDS removal using biliary sphincterotomy dilation (23). It can not be drawn from our study the conclusion that easily removable FCSEMS are better than plastic ones for not removed CBDS even if the cost is much higher.

It was not our aim to make any comparative study. It is only emphasized that a larger volume of drainage can be obtained by inserting one FCSEMS than a plastic stent and it can be useful in some cases of complex CBDS. In addition, our experience for FCSEMS removal almost 200 days after insertion is successful.

In summary, in selected cases, the use of removable FCSEMS is a good choice for a quick and adequate biliary drainage in difficult CBDS. The higher cost of these stents requires individualizing its use. Furthermore, there is a lack of evidence of its effectiveness compared with plastic stents. Randomized studies are necessary in the future.

\section{REFERENCES}

1. Martín-Arranz E, Rey-Sanz R, Martín-Arranz MD, Gea-Rodríguez F, Mora-Sanz P, Segura-Cabral JM. Dilatación con balón asociada a esfinterotomía, evaluación de la eficacia y seguridad en un Hospital terciario. Rev Esp Enferm Dig 2012;104:355-9.

2. Cerefice M, Sauer B, Javaid M, Smith LA, Gosain S, Argo CK, et al. Complex biliary stones: treatment with removable self-expandable metal stents: A new approach (with videos). Gastrointest Endosc 2011; 74:520-6.

3. Fan Z, Hawes R, Lawrence C, Zhang X, Zhang X, Lv W. Analysis of plastic stents in the treatment of large common bile duct stones in 45 patients. Dig Endosc 2011;23:86-90.

4. Han J, Moon JH, Koo HC, Kang JH, Choi JH, Jeong S, et al. Effect of biliary stenting combined with ursodeoxycholic acid and terpene treatment on retained common bile duct stones in elderly patients: a multicenter study. Am J Gastroenterol 2009;104:2418-21.

5. Artifon EL, Aparicio DP, Couto DS, Paione JB. An interim analysis of large metal stents for choledocholithiasis removal in patients with coagulopathy. Gastrointest Endosc 2010;71:AB161.

6. Minami A, Fujita R. A new technique for removal of bile duct stones with an expandable metallic stent. Gastrointest Endosc 2003;57:945-8.

7. Mizukami Y, Saito H, Obara T, Arisato S, Nakano Y, Sakurai, et al. Temporary use of an accuflex stent for unextractable common bile duct stones. Journal of Gastroenterology and Hepatology 2000;15:680-3.

8. García-Cano J, Taberna-Arana L, Jimeno-Ayllón C, Martínez-Fernández R, Serrano-Sánchez L, Reyes-Guevara AK, et al. Use of fully covered self-expanding metal stents for the management of benign biliary conditions. Rev Esp Enferm Dig 2010;102:526-32. 
9. Lauri A, Horton RC, Davidson BR, Burroughs AK, Dooley JS. Endoscopic extraction of bile duct stones: management related to stone size. Gut 1993;34:1718-21.

10. Cheng CL, Tsou YK, Lin CH, Tang JH, Hung CF, Sung KF, et al. Poorly expandable common bile duct with stones on endoscopic retrograde cholangiography. World J Gastroenterol 2012;18:2396-401.

11. Siegel JH, Yatto RP. Biliary endoprostheses for the management of retained common bile duct stones. Am J Gastroenterol 1984;79:50-4

12. Cairns SR, Dias L, Cotton PB, Salmon PR, Russell RC. Additional endoscopic procedures instead of urgent surgery for retained common bile duct stones. Gut 1989;30:535-40.

13. Maxton DG, Tweedle DE, Martin DF. Retained common bile duct stones after endoscopic sphincterotomy: temporary and longterm treatment with biliary stenting. Gut 1995;36:446-9.

14. Chan AC, Ng EK, Chung SC, Lai CW, Lau JY, Sung JJ, et al. Common bile duct stones become smaller after endoscopic biliary stenting. Endoscopy 1998;30:356-9.

15. Soomers AJ, Nagengast FM, Yap SH. Endoscopic placement of biliary endoprostheses in patients with endoscopically unextractable common bile duct stones. A long-term follow up study of 26 patients. Endoscopy 1990;22:24-6.

16. Van Steenbergen W, Pelemans W, Fevery J. Endoscopic biliary endoprosthesis in elderly patients with large bile duct stones: Long-term follow-up. J Am Geriatr Soc 1992;40:57-60.

17. Peters R, Macmathuna P, Lombard M, Karani J, Westaby D. Management of common bile duct stones with a biliary endoprosthesis. Report on 40 cases. Gut 1992;33:1412-5.

18. Chopra KB, Peters RA, O'Toole PA, Williams SG, Gimson AE, Lombard MG, et al. Randomised study of endoscopic biliary endoprosthesis versus duct clearance for bileduct stones in high-risk patients. Lancet 1996;34:791-3.

19. De Palma GD, Catanzano C. Stenting or surgery for treatment of irretrievable common bile duct calculi in elderly patients? Am J Surg 1999;178:390-3.

20. Cotton PB. Stents for stones: Short-term good, long-term uncertain. Gastrointest Endosc 1995;42:272-3.

21. Jain SK, Stein R, Bhuva M, Goldberg MJ. Pigtail stents: An alternative in the treatment of difficult bile duct stones. Gastrointest Endosc 2000;52:490-3.

22. Lee TH, Han JH, Kim HJ, Park SM, Park SH, Kim SJ. Is the addition of choleretic agents in multiple double-pigtail biliary stents effective for difficult common bile duct stones in elderly patients? A prospective, multicenter study. Gastrointest Endosc 2011;74:96-102.

23. García-Cano J, Arana LT, Ayllón CJ, Chicano MV, Fernández RM, Sánchez LS, et al. Biliary sphincterotomy dilation for the extraction of difficult common bile duct stones. Rev Esp Enferm Dig 2009;101:541-5. 